\title{
Role of atresia in establishing the follicular hierarchy in the ovary of the domestic hen (Gallus domesticus)
}

\author{
A. B. Gilbert, M. M. Perry, D. Waddington and M. A. Hardie \\ Agricultural Research Council's Poultry Research Centre, Roslin, Midlothian EH25 9PS, U.K.
}

\begin{abstract}
Summary. At peak laying periods the ovary of the domestic hen contained 30-100 small yolky follicles with diameters varying between 1 and $8 \mathrm{~mm}$. In general, the number of these healthy follicles decreased with increasing size in that there were about 20 follicles with a diameter of $1-2 \mathrm{~mm}$ and 1 follicle (mean $<1$ ) with a diameter of $7-8$ $\mathrm{mm}$. The number of follicles with diameters $>8 \mathrm{~mm}$ (the hierarchy of large, yolky follicles) varied between 4 and 7 . By using a dye-marker, growth from 3 to $5 \mathrm{~mm}$ was estimated to take 3 days, from 5 to $8 \mathrm{~mm}, 2$ days and from $8 \mathrm{~mm}$ to ovulation, 6 days. No information was obtained for growth between 1 and $3 \mathrm{~mm}$ because the dye did not enter these smaller follicles. Between 5 and 25 small yolky follicles were atretic. The reduction in the number of follicles with time and the high incidence of atresia suggests that this is a normal fate of small yolky follicles in birds with a high rate of lay. In marked contrast, only one large yolky follicle was observed to be atretic throughout the whole experiment. These two very different levels of atresia serve to define two distinct groups of follicles in the size range studied. Ovulation rate appears to be the product of two complementary mechanisms, one for the initiation of growth and the other controlling the rate at which the small yolky follicles are lost through atresia.
\end{abstract}

\section{Introduction}

The ovary of the laying hen contains several million follicles (for review see Hutt, 1949) of which several thousand are macroscopically visible (Pearl \& Schoppe, 1921). The present study is concerned with follicles that are $>1 \mathrm{~mm}$ in diameter and are therefore in the vitellogenic phase of development (Marza \& Marza, 1935). Whilst follicles up to $6 \mathrm{~mm}$ or so (small yolky follicles) are susceptible to atresia (Fell, 1923), follicles larger than about $8 \mathrm{~mm}$ (large yolky follicles) normally grow to about $40 \mathrm{~mm}$ and ovulate. Atresia in the latter group is rare for birds at peak reproductive performance, unless some adverse stimulus causes cessation of egg laying. The incidence of atresia in the small yolky follicles is not known for the domestic fowl, but it has been recorded for some seasonally breeding birds (Erpino, 1969, 1973; Kern, 1972). Atresia commonly occurs at the time of breeding in these birds, increasing during the advance of the breeding season to reach a peak at the time of nesting.

However, the significance of atresia in the functioning of the fully active ovary of the fowl can be assessed only within the context of follicular growth patterns. Growth of the large yolky follicles has been extensively studied in the domestic fowl. They are regarded as being in the "rapid-growth phase' and as forming the hierarchy, a succession of several follicles of increasing size (Marza \& Marza, 1935; Warren \& Conrad, 1939; Lacassagne, 1957, 1960; Smith, 1959; Bacon \& Skala, 1968; Gilbert \& Wood-Gush, 1971; Gilbert, 1972; Oribe, 1973). In contrast, the 100 or so small yolky follicles (Romanoff \& Romanoff, 1949; Griffin, Perry \& Gilbert, 1983) have received little attention and estimates of their growth rates vary enormously. Marza \& Marza (1935) considered 
that growth from 3 to $6 \mathrm{~mm}$ took about 60 days, but other studies (Warren \& Conrad, 1939; Oribe, 1973) have indicated that growth from 4 to $7 \mathrm{~mm}$ may take as little as $24 \mathrm{~h}$ to complete. The observations of Opel \& Nalbandov (1958) and of Nalbandov $(1959,1961)$ on the ovarian response to FSH suggest that the time required for growth lies somewhere between these extremes. Injection of FSH led, within a few days, to an increase in number of the small and the large yolky follicles. Similarly, our general observations on the small yolky follicles have indicated that their number is greater than would be expected from a time course as short as $24 \mathrm{~h}$ (Griffin et al., 1983).

A study of the characteristics of the population of small yolky follicles is crucial to an understanding of the formation of the hierarchy of large yolky follicles and, in turn, of egg production in the fowl. We have therefore examined during the peak period of lay a modern laying strain of hen with a high egg yield. The technique of marking follicles with the lipid-soluble dye, Sudan Black B, was employed in the current work, following the method used in earlier studies on growth rates (Warren \& Conrad, 1939; Bacon \& Cherms, 1967, 1968; Bacon \& Skala, 1968; Gilbert, 1972; Oribe, 1973).

\section{Materials and Methods}

Hens (100) of laying stock (Warrens) were housed in individual cages with food and water given $a d$ libitum. Lighting was $14 \mathrm{~h}$ light $(04: 30-18: 30 \mathrm{~h}) / 24 \mathrm{~h}$ day. Two experimental approaches to the problem were tried.

Experiment 1. A random selection of 60 hens was made and each was given a single gelatin capsule (size No. 3, Boots Chemists) containing $100 \mathrm{mg}$ Sudan Black B (Gurr, High Wycombe, U.K.) between $09: 00$ and $10: 00 \mathrm{~h}$, i.e. after the expected ovulation of that day. They were returned to their cages until they were killed by an intravenous injection of an overdose of pentobarbitone sodium (Expiral; Ceva Laboratories, Southampton, U.K.). In a preliminary experiment birds were killed at intervals of 1, 3, 7 and 10 days. From this study it was clear that data from intervening days would be of value. The birds (6/group) were therefore killed at intervals of $1,2,3,4,5$ and 6 days. Follicles $>8 \mathrm{~mm}$ in diameter were removed from the ovary and counted. The remainder of the ovary was briefly rinsed in saline $(9 \mathrm{~g} \mathrm{NaCl} / 1)$ and all follicles $>1 \mathrm{~mm}$, including any that were atretic, were removed and placed in $10 \%$ buffered formalin. Fixation is convenient and does not markedly affect the size of the follicle (Gilbert, Hardie \& Perry, 1982). After the yolk had hardened (2-3 days fixation), the healthy follicles were sized, cut open and scored for the presence or absence of dye. Atretic follicles were not measured because it was impossible to determine the extent of shrinkage of the follicle. The eggs produced by the treated birds were also examined for the presence of dye.

Experiment 2. Twenty-four birds were given a gelatin capsule containing $100 \mathrm{mg}$ Sudan Black B and returned to their cages. All eggs laid for a period of 30 days thereafter were boiled, the yolks bisected and the presence or absence of dye was recorded. Since some birds failed to ingest the dye, there is a discrepancy between the numbers treated and the data in the tables.

\section{Results}

\section{Follicle number}

The ovarian follicles examined in Exp. 1 were divided into 3 categories: follicles $1-8 \mathrm{~mm}$ in diameter, follicles $>8 \mathrm{~mm}$ and atretic follicles. Atretic follicles were distinguished by the occurrence of small haemorrhages on their surface and, in the more advanced stages, by their deformed and/or shrunken appearance. The smallest detectable atretic follicle was $1 \mathrm{~mm}$ and the largest was $8 \mathrm{~mm}$. With one exception, all follicles $>8 \mathrm{~mm}$, i.e. the generally accepted hierarchy, were viable. 
Of the 35 birds with viable follicles (1-8 mm), 7 had 30-40 follicles/ovary, 6 had $41-50,8$ had $51-60,8$ had $61-70,2$ had $71-80,2$ had $81-90$ and 2 had $91-100$; the mean was 56/ovary. The number of atretic follicles ranged from 3 to 26 between birds ( 1 with 3, 8 with 6-10, 12 with 11-15, 7 with 16-20, 5 with $21-25$ and 2 with 26 ) and amounted to about $27 \%$ of the number of viable follicles. Despite the considerable variation between birds in the population of viable follicles (1-8 $\mathrm{mm}$ ), the number in the hierarchy was relatively constant, at 5 or 6 per bird or, rarely, 4 or 7 per bird. Similarly there appeared to be no correlation between the number of atretic follicles and the number in the other categories.

When the viable follicles $(1-8 \mathrm{~mm}$ ) were subdivided into smaller size classes (Table 1), there was a steady decline in the mean number of follicles with increase in size. However, when examined on a per bird basis, this decline was less regular within individuals, although the tendency for there to be fewer follicles of larger size was still apparent. More than half the birds had no follicle in the largest size class, but several birds had 2 follicles, and in one instance 4 follicles, in this size class.

Table 1. Size gradations in the population of viable follicles between 1 and $8 \mathrm{~mm}$ in diameter in the hen's ovary (Exp. 1)

\begin{tabular}{llccccccc}
\hline & \multicolumn{7}{c}{ Follicular diameter (mm) } \\
\cline { 2 - 8 } & $>1-2$ & $>2-3$ & $>3-4$ & $>4-5$ & $>5-6$ & $>6-7$ & $>7-8$ \\
\hline No. of follicles & Mean & $21 \cdot 8$ & $13 \cdot 3$ & $8 \cdot 4$ & $4 \cdot 8$ & $4 \cdot 1$ & $2 \cdot 4$ & $0 \cdot 6$ \\
& s.d. & $9 \cdot 5$ & $5 \cdot 3$ & $4 \cdot 3$ & $2 \cdot 6$ & $2 \cdot 9$ & $1 \cdot 4$ & $0 \cdot 8$ \\
Range & $8-48$ & $4-25$ & $2-19$ & $1-11$ & $1-11$ & $0-5$ & $0-4$ \\
$\begin{array}{l}\text { No. of birds with one or more } \\
\text { follicles in the category }\end{array}$ & 35 & 35 & 35 & 35 & 35 & 31 & 16 \\
\hline
\end{tabular}

\section{Follicular growth rate}

Observations on ovaries. An estimate of the growth rate of the small yolky follicles was obtained in the first instance by administering a single dose of Sudan Black to birds on Day 0 and determining the time taken for the dyed follicles to develop in the ovary. Observations at early times after administration provided evidence that the dye was taken into the follicles as a pulse lasting not more than $24 \mathrm{~h}$. On Day 1 , the dye was present in most follicles $>3 \mathrm{~mm}$. It was located in the outer zone of yolk and extended to depths of approximately $0.5-1 \mathrm{~mm}$, depending on the size of the follicle. On Day 2 there was no label in follicles of 3-4 mm, or in the outer layer of previously dyed follicles $>5 \mathrm{~mm}$. At this time the staining patterns differed according to follicular size. In follicles $>6 \mathrm{~mm}$ the dye remained in a discrete layer, in follicles of 5-6 $\mathrm{mm}$ it had diffused inwards, staining the yolk core, and in follicles of $4-5 \mathrm{~mm}$ the entire yolk mass was lightly stained. These patterns persisted in follicles examined at later times, the smaller follicles containing a lightly stained yolk core and the larger follicles an intensely stained layer, seen as a ring in cross-section. This differential staining pattern reflects the change in yolk composition at the 4-5-mm stage of growth (Marza \& Marza, 1935) resulting in a stable conformation of the yolk layers deposited subsequently (Warren \& Conrad, 1939).

The proportion of labelled follicles in the ovary decreased with time; on Day 6 none were present in the 3-8 mm classes and on Day 10 few remained in the $8-40 \mathrm{~mm}$ class. The data from Exp. 1 (Tables $2 \& 3$ ) were consistent with the preliminary findings and showed that growth from 3 to $8 \mathrm{~mm}$ took about 5 days to complete. Three individual examples of birds examined at successive time intervals (Table 2) serve to show the general pattern of growth, though some variation (Table 3) was encountered between birds. For any given bird, irrespective of the time elapsed, there was a distinct demarcation in size between the labelled and unlabelled follicles, all those above a certain size containing dye. This observation indicates that growth of the follicles is synchronous. Their rate of progression from one size class to the next can be determined by measuring either the 
smallest dyed follicle or the largest unlabelled follicle in each ovary on any given day, as shown in Table 3. Since, however, many follicles are destined to become atretic and follicles in the earliest stages of the process are not detectable, the method may be biased, i.e. taking the smallest follicle gives an overestimate of growth if all dyed follicles in the class below it have regressed and an underestimate of growth if it is becoming atretic. Alternatively, taking the largest unlabelled follicle gives an overestimate of growth if it is becoming atretic (e.g. the unlabelled follicle in the 5$6 \mathrm{~mm}$ class on Day 1 in Table 3), and an underestimate of growth if all the unlabelled follicles in the size class above it have regressed. The first and last of these 4 sources of error become increasingly likely in the later part of the growth phase.

Table 2. Three examples of ovaries from individual birds examined at given intervals after a single administration of Sudan Black B to show the number per size class of undyed and dyed viable follicles

(Exp. 1)

\begin{tabular}{clrccccccc}
\hline \multirow{2}{*}{$\begin{array}{c}\text { Interval } \\
\text { (days) }\end{array}$} & Follicle & $>1-2$ & $>2-3$ & $>3-4$ & $>4-5$ & $>5-6$ & $>6-7$ & $>7-8$ & $>8-40$ \\
\cline { 2 - 9 } & & & \multicolumn{7}{c}{ Follicular diameter (mm) } \\
\hline \multirow{2}{*}{1} & Undyed & 16 & 20 & 0 & 0 & 0 & 0 & 0 & 0 \\
& Dyed & 0 & 0 & 4 & 3 & 1 & 2 & 1 & 5 \\
& Undyed & 26 & 21 & 4 & 11 & 6 & 0 & 0 & 0 \\
& Dyed & 0 & 0 & 0 & 0 & 2 & 1 & 2 & 6 \\
& Undyed & 35 & 16 & 9 & 7 & 7 & 3 & 1 & 1 \\
& Dyed & 0 & 0 & 0 & 0 & 0 & 0 & 0 & 4 \\
\hline
\end{tabular}

Table 3. Number of birds, according to the maximum size of undyed follicles (in parentheses) and the minimum size of dyed follicles in the ovary, at given intervals after dye administration (Exp. 1)

\begin{tabular}{ccccccccc}
\hline & & \multicolumn{7}{c}{ Follicular diameter (mm) } \\
\cline { 3 - 8 } $\begin{array}{c}\text { Interval } \\
\text { (days) }\end{array}$ & $\begin{array}{c}\text { Total no. } \\
\text { of birds }\end{array}$ & $>2-3$ & $>3-4$ & $>4-5$ & $>5-6$ & $>6-7$ & $>7-8$ & $>8-40$ \\
\hline 1 & 4 & $(2)$ & $(1) 2$ & 2 & $(1)$ & & \\
2 & 6 & & & $(4) 6$ & $(2)$ & & \\
3 & 6 & & & $(3)$ & $(3) 5$ & 1 & \\
4 & 5 & & & $(2)$ & $(3) 5$ & & \\
5 & 6 & & & & $(4) 3$ & $(2) 3$ & \\
6 & 6 & & & & & $(5)$ & $(1) 6$ \\
\hline
\end{tabular}

An indication of the rate of resorption of atretic follicles was given by the length of time during which dyed, atretic follicles persisted in the ovary. On Day 1, dyed follicles comprised about half the number of atretic follicles, some were still evident on Day 3 and by Day 6 they were no longer present.

Although the criterion of dye marking is only applicable to the resorption of yolk and not to the follicle as a whole, these observations do suggest that the atretic follicles are eliminated from the ovary within several days. The observable loss of labelled viable follicles from the ovary through atresia amounted to some $40 \%$ in the 5-day period.

Observations on eggs. In Exp. 2, an estimate of the growth rate was obtained from the length of time during which eggs containing dyed yolk were laid by birds given a single dose of Sudan Black B on Day 0. Eggs containing dye were produced for a period ranging from 9 to 13 days, depending on individual birds (Table 4a). They showed progressive changes in the dye pattern, as described by Oribe, Kameyama \& Kayano (1975) and a sharp demarcation in time between the last labelled yolk and the first unlabelled yolk. On Day 2 a narrow zone of superficial yolk was dyed and appeared as a ring in cross-section. On each successive day, for an average period of 8 days (Table $4 \mathrm{~b}$ ), the ring was smaller, and at later times it was usually less regular in shape. This result is in agreement with 
previous estimates for the period of production of eggs with dye rings that were used to determine the length of the rapid growth phase (Warren \& Conrad, 1939; Lacassagne, 1960; Bacon \& Skala, 1968; Gilbert, 1972; Oribe, 1973). The inner diameter of the smallest regular dye ring was about 5 $\mathrm{mm}$. In eggs laid on the following 3 days (Table 4c), a central core of yolk, measuring 4-5 mm in diameter in the least distorted specimens, was diffusely stained. This value of 3 days broadly corresponded with the time determined for growth of the ovarian follicles from 3 to $5 \mathrm{~mm}$ (Tables 2 $\& 3$ ), the phase when follicular yolk exhibited diffuse staining.

Table 4. Frequency distribution of 23 birds according to the duration of production of dyed eggs* after a single administration of Sudan Black B (Exp. 2)

\begin{tabular}{lcccccrr}
\hline (a) Total period of production of dyed eggs & & \\
No. of days & 8 & 9 & 10 & 11 & 12 & 13 & 14 \\
No of birds & 0 & 2 & 5 & 1 & 12 & 3 & 0 \\
(b) Period of production of eggs & with & a & definitive & dye & ring & in yolk \\
No. of days & 6 & 7 & 8 & 9 & 10 & 11 & 12 \\
No of birds & 0 & 8 & 8 & 2 & 4 & 1 & 0 \\
(c) Period of production of eggs & with & a diffusely-dyed yolk core \\
No. of days & 1 & 2 & 3 & 4 & 5 & 6 \\
No of birds & 0 & 7 & 7 & 7 & 2 & 0 \\
\hline
\end{tabular}

* The average egg production rate was $85 \%$.

The ordered sequence of production of dyed eggs was a notable feature of this experiment and indicated an ordered growth from a follicle diameter of $3 \mathrm{~mm}$ upwards. Thus, no undyed eggs were produced in the middle of a sequence of dyed eggs, or vice versa. Similarly, there was no interruption in the progressive change of dye patterns in the yolk. For instance, no egg was obtained with a larger ring than that laid previously, nor were eggs with yolk rings produced in the middle of a sequence with dyed yolk cores.

\section{Discussion}

The present work has provided information regarding several aspects of ovarian function in the domestic hen which hitherto have received little attention. Although birds from only one laying strain were used, the work does provide a basis for comparisons to be made with other types. For example, a similar study on broiler chickens or turkeys may provide an explanation for the relatively poor egg production of these and it would be possible to determine whether the decline in egg production with age in laying strains is brought about by changes in one or other of the operative mechanisms present (e.g. rate of atresia).

At peak production the hen's ovary contains about 60 follicles between 1 and $8 \mathrm{~mm}$ (small yolky follicles). However, it was observed that there was a tendency for the number of follicles in each size class to decrease with increasing size of the follicle. Follicular growth appears to be continuous from the stage of $3 \mathrm{~mm}$ to ovulation and, despite variation between birds, the following approximations obtained from the data serve as a general guide to the length of the growth phases: from 3 to $5 \mathrm{~mm}, 3$ days (Table 4c); from 5 to $8 \mathrm{~mm}, 2$ days (Tables $3 \& 4 \mathrm{c}$ ); from $8 \mathrm{~mm}$ to ovulation, 6 days (Tables $3 \&$ $4 a)$. Since follicles $<3 \mathrm{~mm}$ failed to take up the Sudan dye, it was not possible to obtain estimates of the growth rate of follicles between 1 and $3 \mathrm{~mm}$.

As suggested previously (Gilbert, 1971), the small yolky follicles do not constitute a conventional 'pool' nor are they in a 'resting' state. If a true resting state does exist, it must occur in follicles of diameters less than $1 \mathrm{~mm}$. Follicles $>3 \mathrm{~mm}$ diameter, and probably also those $>1 \mathrm{~mm}$, grow such that all the follicles of a size group develop together and in a consistent way in relation to 
those in other size groups. Moreover, our estimate of about 5 days for the time course for growth from 3 to $8 \mathrm{~mm}$, obtained more directly than previously, is appreciably shorter than that suggested by Marza \& Marza (1935) but longer than the $24 \mathrm{~h}$ suggested from consideration of dye-rings (Warren \& Conrad, 1939; Oribe, 1973).

There is a general decrease in the number of follicles present in the ovary as the follicles increase in size and about $50 \%$ of the hens had no follicles in the 7-8-mm size range. This may account for the gaps which are a common feature in the sequence of the larger follicles in the hen and which appear to regulate the rate of lay (Warren \& Conrad, 1939; Lacassagne, 1960; Gilbert \& WoodGush, 1971; Gilbert, 1972). However, the number of such birds is too high for laying rates of $80 \%$ or more, and, therefore it is possible that the $7-8 \mathrm{~mm}$ class corresponds to less than 1 day's growth.

Of considerable importance to an understanding of ovarian function generally was the quantification of atresia in the small yolky follicles; most previous reports, although recognizing that atresia was a common feature of avian ovaries, failed to give this information (Dubuisson, 1906; Fell, 1925; Davis, 1942; Moreau, Wilk \& Rowan, 1947; Romanoff \& Romanoff, 1949; Marshall, 1957; Lofts \& Murton, 1973; Gilbert, 1979). Usually about 10-15 atretic follicles were visible with a maximum of about 30 . This figure almost certainly excludes follicles which were in the initial or terminal stages of atresia and which could not be identified by visual examination. The major incidence of atresia in seasonally breeding birds occurs during nesting when the ovary is regressing (Erpino, 1969, 1973; Kern, 1972). The hens in the present study were at the peak of their laying yet still showed a high incidence of atresia.

The follicle which ovulates each day is the survivor of the initial number starting their growth phase at about $1 \mathrm{~mm}$ or less. Within the ovary there are about 20 follicles between 1 and $2 \mathrm{~mm}$ at any one time, although it is not certain that this represents exactly the initial production for 1 day. Nevertheless, some assessment can be made of the potential of the ovary to continue to produce ovulable follicles. In a full laying life of about 8 years a laying hen may produce up to about 1500 eggs (Romanoff \& Romanoff, 1949). If 20 follicles are produced for each one that ovulates, then something of the order of 30000 follicles will be required. Yet this represents only about $2 \%$ of the total number of follicles contained within the ovary (Hutt, 1949). In common with other vertebrates, therefore, the hen produces more oocytes than are required and eliminates the excess through atresia (Greenwald, 1978; Jones, 1978).

Atresia usually occurs only in the smaller follicles long before they reach ovulable size. Consequently, the hierarchy, which determines the number of follicles which can be ovulated in any period, is the product of the number of follicles produced for growth (those about $1 \mathrm{~mm}$ ) and the rate of atresia during the increase in size up to about $8 \mathrm{~mm}$. Hence two complementary mechanisms are present, each of which plays an important part in regulating the capacity of the ovary to produce follicles which are destined to ovulate. There is little information about the factors that control either the initial number of follicles entering the growth phase or the rate of atresia thereafter. Although FSH is almost certainly involved in follicular growth (for discussion see Gilbert, 1971; Lofts \& Murton, 1973), its precise mechanism and its site of action within the ovary are unknown.

The larger yolky follicles ( $>8 \mathrm{~mm}$ diameter) were thought previously to be different from the small yolky follicles in that they grew sequentially at a rapid rate and that they contained yellow yolk. However, the small yolky follicles are also growing rapidly at a rate of increase in diameter of about $1 \mathrm{~mm}$ a day and these follicles contain at least a proportion of yellow yolk (Griffin et al., 1983). Moreover there is a hierarchical arrangement according to size, although there are more follicles in each size group than the single follicle for sizes $>8 \mathrm{~mm}$. Consequently the growth of follicles from as small as $3 \mathrm{~mm}$, and possibly smaller, is an orderly one up to ovulation.

Nevertheless, there is an important distinction between follicles with diameters $>8 \mathrm{~mm}$ and those smaller than this. The usual fate of the large yolky follicles is ovulation; under normal conditions during the laying period, the large yolky follicles of the domestic hen do not become atretic. In contrast, atresia seems to be the usual alternative to growth in what appear to be normal small yolky follicles. The physiological differences that distinguish the two groups are not known. However, in follicles of about $8 \mathrm{~mm}$ the granulosa cells may be changing their function because they 
stop producing the transosomes, the specialized bodies that are transferred to yolk-forming oocytes (Griffin et al., 1983), and the first indications of steroid dehydrogenases are seen (Davidson, Gilbert \& Wells, 1979). Whether these observations are directly related to the ability of a follicle to resist atresia or are merely indicative of a change in state must await further investigation.

\section{References}

Bacon, W.L. \& Cherms, F.L. (1967) The relationship of light stimulation to ovarian development and ovulation in turkey hens. Poult. Sci. 46, 1230.

Bacon, W.L. \& Cherms, F.L. (1968) Ovarian follicular growth and maturation in the domestic turkey. Poult. Sci. 47, 1303-1314.

Bacon, W.L. \& Skala, J.H. (1968) Ovarian follicular growth and maturation in laying hens and the relation to egg quality. Poult. Sci. 47, 1437-1442.

Davidson, M.F., Gilbert, A.B. \& Wells, J.W. (1979) The activity of the ovarian $\Delta^{5}-3 \beta$-hydroxysteroid dehydrogenase in the domestic fowl (Gallus domesticus) with respect to age. J. Reprod. Fert. 57, 61-64.

Davis, D.E. (1942) The bursting of avian follicles at the beginning of atresia. Anat. Rec. 82, 153-161.

Dubuisson, H. (1906) Etudes de vitellus. Archs Zool. exp. gén. 5, 153-402.

Erpino, M.J. (1969) Seasonal cycle of reproductive physiology in the black-billed magpie. Condor 71, 267-279.

Erpino, M.J. (1973) Histogenesis of atretic ovarian follicles in a seasonally breeding bird. J. Morph. 139, $239-250$.

Fell, H.B. (1923) Histological studies on the gonads of the fowl. Br. J. exp. Biol. 1, 3-16.

Fell, H.B. (1925) Histological studies on the gonads of the fowl. Q. Jl microsc. Sci. 69, 591-609.

Gilbert, A.B. (1971) The ovary. In The Physiology and Biochemistry of the Domestic Fowl, Vol. 3, pp. 11631208. Eds D. J. Bell \& B. M. Freeman. Academic Press, London.

Gilbert, A.B. (1972) The activity of the ovary in relation to egg production. In Egg Formation and Production, pp. 3-21. Eds B. M. Freeman \& P. E. Lake. British Poultry Science, Edinburgh.

Gilbert, A.B. (1979) Female genital organs. In Form and Function in Birds, Vol. 1, pp. 237-360. Eds A. S. King \& J. McLelland. Academic Press, London.

Gilbert, A.B. \& Wood-Gush, D.G.M. (1971) Ovulatory and ovipository cycles. In The Physiology and Biochemistry of the Domestic Fowl, Vol. 3, pp. 1353 1378. Eds D. J. Bell \& B. M. Freeman. Academic Press, London.

Gilbert, A.B., Hardie, M.A. \& Perry, M.M. (1982) The relationship between the weight and diameter of the small ovarian follicles of the domestic hen (Gallus domesticus). IRCS Med. Sci. 10, 571.

Greenwald, G.S. (1978) Follicular activity in the mammalian ovary. In The Vertebrate Ovary, pp. 639-689. Ed. R. E. Jones. Plenum Press, New York.

Griffin, H.D., Perry, M.M. \& Gilbert, A.B. (1983) Yolk formation. In The Physiology and Biochemistry of the Domestic Fowl, Vol. 4. (in press). Ed. B. M. Freeman. Academic Press, London.

Hutt, F.B. (1949) Genetics of the Fowl. McGraw-Hill, New York.
Jones, R.E. (1978) Ovarian cycles in non-mammalian vertebrates. In The Vertebrate Ovary, pp. 731-762. Ed. R. E. Jones. Plenum Press, New York.

Kern, M.D. (1972) Seasonal changes in the reproductive system of the female white-crowned sparrow, Zonotrichia leucophrys gambelii, in captivity and in the field. Z. Zellforsch. mikrosk. Anat. 126, 297-319.

Lacassagne, L. (1957) Dynamique de l'ovogenèse. Contribution à l'étude de la phase de grand accroissement des follicules chez la poule domestique. Annls Zootech. 2, 85-93.

Lacassagne, L. (1960) Étude comparée des réserves vitellines et de la durée de la phase de grand accroissement de l'ovocyte chez la poule domestique. Annls Zootech. 9, 85-96.

Lofts, B. \& Murton, R.K. (1973) Reproduction in birds. In Avian Biology, Vol. III, pp. 1-107. Eds D. S. Farner \& J. R. King. Academic Press, New York.

Marshall, A.J. (1957) The interaction of environmental, internal and behavioural factors in the rook, Corvus $f$. frugilegus Linnaeus. Proc, zool. Soc. Lond. 128, 545589.

Marza, V.D. \& Marza, E.U. (1935) The formation of the hen's egg. $Q$. $J l$ microsc. Sci. 78, 134-189.

Moreau, R.E., Wilk, A.L. \& Rowan, W. (1947) The moult and gonad cycles of three species of birds at five degrees south of the equator. Proc. zool. Soc. Lond. 117, 345-364.

Nalbandov, A.V. (1959) Neuroendocrine reflex mechanisms: bird ovulation. In Comparative Endocrinology, pp. 161-173. Ed. A. Gorbman. John Wiley, New York.

Nalbandov, A.V. (1961) Mechanisms controlling ovulation of avian and mammalian follicles. In Control of Orulation, pp. 122-131. Ed. C. A. Villee. Pergamon Press, London.

Opel, H. \& Nalbandov, A.V. (1958) A study of hormone growth and ovulation of follicles in hypophysectomised hens. Poult. Sci. 37, 1230-1231.

Oribe, T. (1973) On the speed of the accumulation of egg yolk in the chicken egg. Bull. Hiroshima agric. Coll. 4, 323-331.

Oribe, T., Kameyama, K. \& Kayano, K. (1975) On the morphology of sudan layer formed in the egg after feeding Sudan III. Bull. Hiroshima agric. Coll. 5, 189 199.

Pearl, R. \& Schoppe, W.F. (1921) Studies on the physiology of reproduction in the domestic fowl. XVIII. Further observations on the anatomical basis of fecundity. J. exp. Zool. 34, 101-118.

Romanoff, A.L. \& Romanofi, A.J. (1949) The Avian Egg. John Wiley, New York.

Smith, A.H. (1959) Follicular permeability and yolk formation. Poult. Sci. 38, 1437-1446.

Warren, D.C. \& Conrad, R.M. (1939) Growth of the hen's ovum. J. agric. Res. 58, 875-894.

Downloaded from Bioscientifica.com at 04/26/2023 12:51:24PM 